\title{
O Sistema Transtonal em Metalosfera, de Almeida Prado
}

\author{
The Transtonal System in Metalosfera, by Almeida Prado
}

\author{
Robson Alexandre de Nadai \\ Universidade Estadual de Campinas \\ radenadai@uol.com.br
}

\section{Rita de Cássia Taddei}

taddei.rita@gmail.com

\begin{abstract}
Resumo: Este artigo apresenta inicialmente o Sistema Transtonal, criado pelo compositor Almeida Prado e empregado na peça Metalosfera. Por meio da análise de material esclarecemos o tripé que fundamenta o uso desse sistema de composição na obra: a ressonância de blocos sonoros e a importância dos harmônicos para efeitos timbrísticos; "neocadências" e a ocorrência de conclusões ambíguas. Especificamente na peça analisada, essa investigação aponta que o primeiro material empregado é um intervalo de 5J, ao qual se agrega uma $3 \mathrm{M}$, portanto uma estrutura tonal. No desenvolvimento da obra esse intervalo de $3 \mathrm{M}$ se converte ora em $2 \mathrm{~m}$, ora $4 \mathrm{~A}$, sintetizando o material que é desenvolvido na peça e indicando implicações para o sistema atonal. O trabalho destaca Almeida Prado como o proponente do Transtonalismo, apontando principalmente o fato deste sistema fundir estruturas tonais e atonais, trazendo o fator ambiguidade como meio de agregar técnicas opostas.
\end{abstract}

Palavras-chave: transtonalismo; neocadência; Almeida Prado.

\begin{abstract}
This articlestarts presenting the Transtonal System, created by the composer Almeida Prado and applied to the piece Metalosfera. Through the analysis of the material, we clarify the tripod that justifies the use of this compositional system in this piece of music: the resonance of sound blocks and the importance of harmonics to timbre effects; "neocadences" and the occurrence of ambiguous endings. Specifically, in the analyzed piece, this investigation points out that the first employed material is a P5 interval, to which is added a M3, thus a tonal structure. In the development of the work, the M3 interval becomes or a m2 or an Aug4, synthesizing the material that is developed in the piece and indicating implications for the atonal system. The article highlights Almeida Prado as the proponent of the Transtonalism, pointing mainly to the fact that this system fuses tonal and atonal structures, bringing the ambiguity factor as a way to mix opposing techniques.
\end{abstract}

Keywords: transtonalism; neocadence; Almeida Prado. 


\section{1 - Introdução}

Almeida Prado, um dos principais compositores brasileiros da segunda metade do século $X X$, tem uma extensa produção dentro do repertório de música de câmara para instrumentos de metal, de fato uma produção diversificada e direcionada a formações sui generis. Sua escrita musical é desafiadora e oferece ao intérprete uma linguagem instrumental tecnicamente bem definida.

Este trabalho visa esclarecer a forma como se estrutura o Transtonalismo, bem como demonstrar o seu emprego na obra Metalosfera (Almeida Prado 1982). Focando aspectos de ressonância de blocos sonoros e o uso de caminhos harmônicos singulares, que o próprio compositor denominou de "neocadências", o artigo apresenta uma análise dos materiais empregados na peça.

Metalosfera abrange características específicas na escrita dos metais e foi obra preambular no protagonismo desse naipe de instrumentos dentro do repertório camerístico de Almeida Prado. Elaborada para nove instrumentos de metal - três trompetes, três trompas e três trombones -, possui três movimentos: Convocação - uma chamada para uma cerimônia sonora, arcaica, mágica, fora do tempo; Variações - uma série de metamorfoses sobre uma pequena série de 13 sons, onde em cada uma, a série se transmuta em cores diferentes; Coral-grandes acordes se formam, pouco a pouco, em arcos, como a solidez e a austeridade de uma catedral gótica.

Esperamos neste trabalho exemplificar como funciona uma estruturação através do sistema Transtonal, bem como contribuir para realçar sua importância dentro dos processos analíticos da obra do compositor.

\section{2 - Transtonalismo}

O sistema Transtonal, criado por Almeida Prado, enfatiza principalmente a questão das ressonâncias, aspecto relevante na análise da peça Metalosfera. $\mathrm{O}$ compositor se utiliza de caminhos harmônicos díspares para a proposição de uma centralidade tonal, o que chama de "neocadências", criando sempre um contexto ambíguo no que se refere à definição desse centro, o que é outra característica deste sistema e de sua técnica de composição.

O espaço sonoro ocupado pelo tonalismo serviu de suporte para inúmeras gerações de compositores. Em uma constante repetição, redundância estrutural, baseada no ponto de partida e de retorno à tônica de um determinado tom, o discurso musical se desenvolvia através de outros caminhos chamados de modulações - instalações provisórias em determinadas regiões que davam a sensação de que o centro tonal havia mudado. O discurso de Almeida Prado sobre o tonalismo propõe: 
O tonalismo, sem dúvida alguma, visava sobretudo uma linguagem onde os elementos Arsis (dissonância)e Thesis (sonância) se articulariam numa constante dialética de contrastes (Almeida Prado 1985).

Neste caminho, compositores como Mozart, Beethoven, Schumann, Liszt, Brahms, entre outros, realizaram suas trajetórias inserindo acordes alterados e cromatismos ao sistema tonal, porém sempre estando presente a dialética entre Tônica e Dominante.

Segundo Almeida Prado, o Transtonalismo - termo cunhado pelo compositor $^{1}$ - refere-se à repetição como forma de memorização e da compreensão musical. Dessa forma, em sua obra, predominantemente atonal, essa repetição pode ocorrer no excesso de ressonâncias ou na insistência em determinado acorde. Esta técnica foi sedimentada pela primeira vez na obra Cartas Celestes I.

A escuta de uma obra atonal não dá ao ouvinte, nunca, a sensação de recuperar determinado acorde, aquele elemento simples e óbvio que tece uma articulação do discurso tonal. [...] As cadências, elemento vital do Tonalismo, ficam relegadas ao total esquecimento com o advento do Atonalismo. [...] O meu sistema seria então, uma tentativa de colocar juntos as experiências atonais com o uso racional dos Harmônicos Superiores e Inferiores, criando Zonas de Percepção das Ressonâncias (Almeida Prado 1985a).

Em sua tese de doutorado (Almeida Prado 1985a) teorizou que o sistema de ressonâncias é organizado com uma divisão em várias zonas: zona de ressonância explícita, implícita, múltipla e zona de não ressonância. Com isso, o funcionamento do discurso sonoro no Sistema Transtonal fica...

rico de aquisições múltiplas ao mesmo tempo, atento a uma organização do espaço sonoro, muito mais cheio de unidade, e colocando o elemento da redundância como fator primordial e gerador das ressonâncias (Almeida Prado 1985a).

De acordo com Almeida Prado, vários elementos sonoros (ritmo, sobreposição de acordes que geram ressonância e estrutura intervalar) interagem no discurso musical de forma insistente e, por serem repetidos obstinadamente, resultam numa assimilação do discurso sonoro por parte do ouvinte. Esclarecemos que a análise apresentada neste artigo focará exatamente nesses elementos do Transtonalismo.

Quanto ao termo "neocadência", insere-se na linguagem musical de Almeida Prado para expor quais caminhos a estrutura harmônica realiza para

\footnotetext{
${ }^{1}$ Essa atribuição, entretanto, não é unânime. Disputa-se que o musicólogo Yulo Brandão tem precedência sobre o compositor na criação do conceito.
} 
alcançar os centros tonais em determinada peça (Metalosfera, no caso deste trabalho), haja vista que o compositor utiliza aspectos do tonal e do atonal e ressalta a necessidade de uma Neocadência para a compreensão do discurso sonoro. Conforme explica Mariz:

Julga ele, em entrevista à revista Visão (3-9-79), que "o importante é o som, e o segredo está no uso do sistema transtonal", um tipo de música que incorpora as técnicas clássicas e românticas, as experiências contemporâneas e "acaba sendo a mesma coisa que o público tem o hábito de ouvir - como Beethoven, por exemplo - mas diferente". Acha o compositor que só agora se assenhorou de um estilo próprio. Esse sistema leva em conta as ressonâncias naturais, todos os fatores acústicos e a necessidade de uma neocadência para que "o discurso musical tenha uma entonação mais evidente e mais simples para quem ouve". (Mariz 2004, p. 399).

Para esta investigação é necessário pontuar que a peça Metalosfera foi estruturada com blocos sonoros sobrepostos com maior ou menor duração. Independentemente dessas durações, é importante considerar todas essas sobreposições para a análise, pois a peça se refere a um período composicional de Almeida Prado que dá grande importância à questão dos harmônicos resultantes. Esta aglomeração de alturas estrutura grandes blocos sonoros que conferem à obra uma textura coral densa, apropriada à linguagem dos metais.

Considerando todos os elementos estruturais apontados na organização desse sistema, apresentamos a análise da peça como forma de elucidar concretamente a aplicação do Transtonalismo.

\section{3 - Análise}

Metalosfera organiza-se em três movimentos. O primeiro movimento, uma fanfarra, está organizado em duas seções e coda. O segundo apresenta-se no formato de tema e oito variações, e o terceiro movimento está escrito em textura coral.

As seções do primeiro movimento são estabelecidas pelos seus respectivos centros transtonais. A primeira seção tem como centro a altura Dó, a segunda seção a altura Sol e a terceira seção a altura Ré. Esses centros são alcançados por meio de "neocadências", conforme mostraremos na análise dos materiais que se segue.

O primeiro movimento se inicia com as alturas Dó-Sol nas trompas, pontuando o início da $1^{\text {a }}$ seção (compassos 1-27), conforme mostra o Exemplo $1^{2}$.

\footnotetext{
${ }^{2}$ Todos as alturas das Exemplos se encontram com o som real.
} 


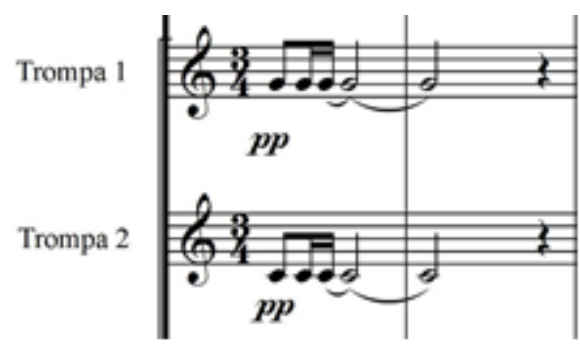

Exemplo 1: Almeida Prado, Metalosfera, c. 1-2 - intervalo de 5J

A partir da apresentação deste material, ou seja, um mero intervalo de 5J, que se considera o germe para a construção deste movimento, nota-se a sua expansão, que se dá, primeiramente, pelo acréscimo da $3 \mathrm{M}$, resultando em uma tríade maior (Dó-Mi-Sol).

Cria-se, portanto, o primeiro bloco sonoro, ao qual serão agregados novos blocos no decorrer do movimento: Sib-Ré-Fá e Si-Re\#-Fá\# (compondo, portanto, uma relação intervalar de $2 \mathrm{~m}$ entre os dois agregados), para resultar em sonoridades produzidas pelas ressonâncias dos harmônicos. Ressaltamos que em todos os blocos sonoros o intervalo de quinta justa é constante, portanto, para esta análise, consideramos este intervalo como fator preponderante e elemento que confere unidade à construção da obra. Observe-se isso no Exemplo 2.
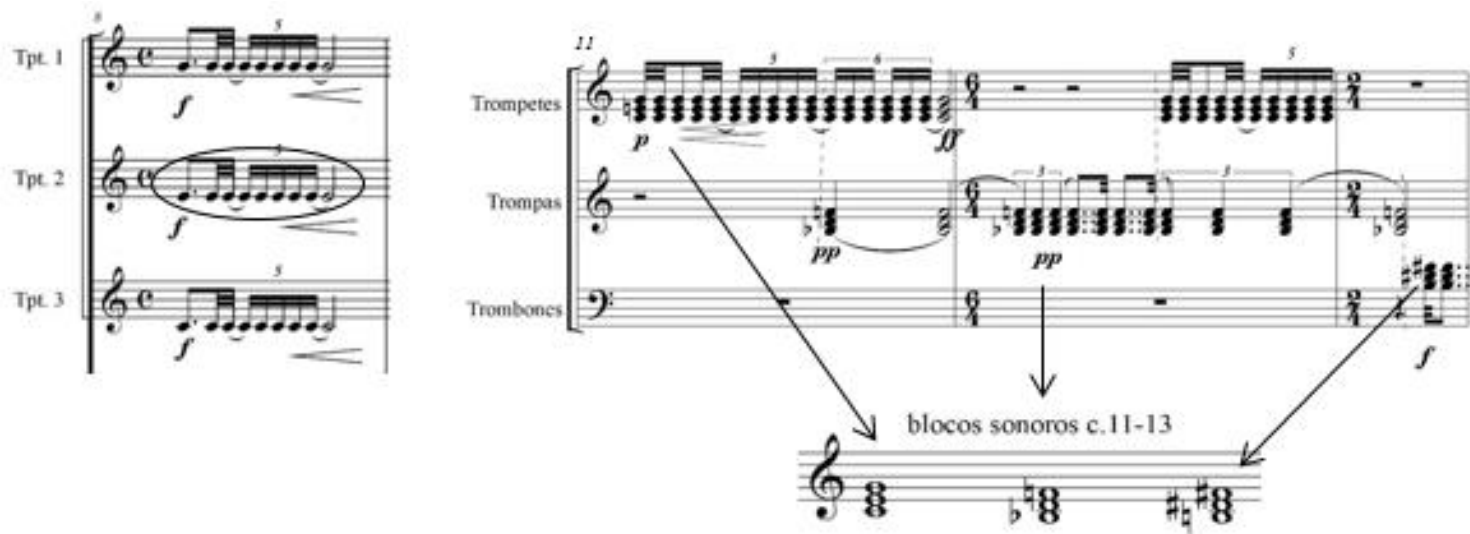

Exemplo 2: Almeida Prado, Metalosfera

Inserção da 3M ao intervalo de 5J e sobreposição de três blocos sonoros

No compasso 25, nota-se o retorno ao intervalo de 5J, havendo, portanto, a supressão do intervalo de 3M. Isso implica no retorno de uma área de grande ressonância para uma área de pequena ressonância. Além disso, as alturas se modificam, Sol-Ré nos trompetes e Mib-Sib nas trompas, indicando o caminho estrutural para um novo centro, Sol. Encerra-se assim a primeira seção da peça.

No que tange à questão da "neocadência" nesta seção, destacamos o caminho que Almeida Prado utiliza para apontar o novo centro. Partindo dos blocos Dó-Mi-Sol (trompetes), são acrescidas as alturas Sib-Ré-Fá (trompas) e Si 
-Ré\#-Fá\# (trombones) formando um bloco sonoro que gera ressonâncias numa coleção cromática que se estende de Sib a Sol. Dentro deste procedimento destacamos a utilização de dois formatos cadenciais intercalados para apontar o novo centro da peça: o bloco sonoro Dó-Mi-Sol que pode ser considerado a Subdominante de Sol e os blocos sonoros Sib-Ré-Fá e Si-Ré\#-Fa\# que correspondem respectivamente à Dominante e à Napolitana da Dominante de $\mathrm{Mib}^{3}$. Na sequência, o compositor apresenta dois possíveis centros provisórios. Essa ambiguidade é resolvida com a consolidação do centro Sol.

Neste trecho Almeida Prado utiliza de vários procedimentos inerentes ao sistema Transtonal: fusão do tonal com o atonal; utilização de ressonâncias predominantemente de $2 \mathrm{~m}$; utilização da ambiguidade como elemento de conclusão das cadências. O Exemplo 3 resume esses procedimentos.

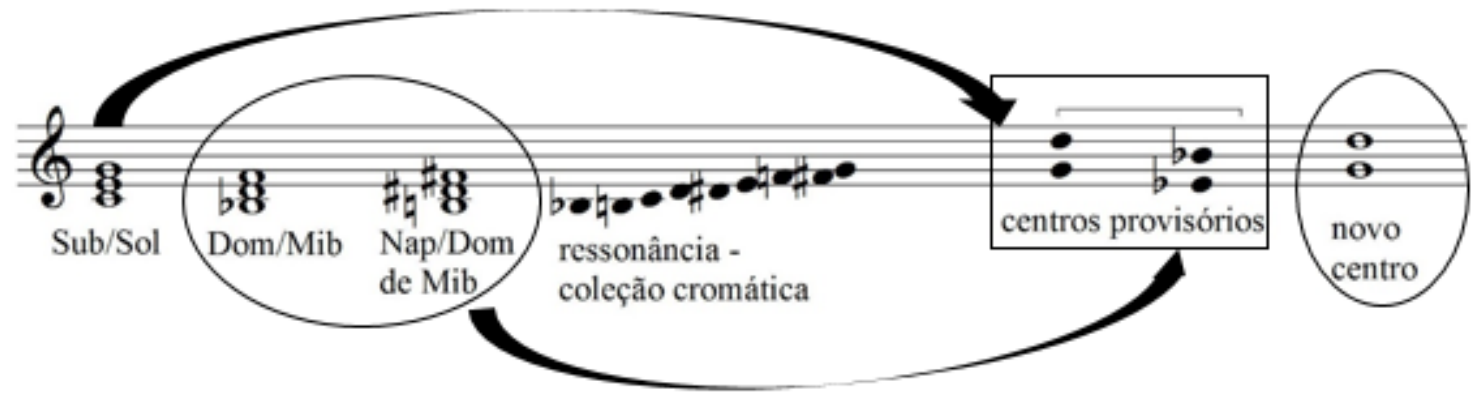

Exemplo 3: Almeida Prado, Metalosfera - Neocadência da $1^{\underline{a}}$ seção

Inicia-se a segunda seção da peça (compassos 28-38) apresentando o bloco sonoro Sol-Ré, ratificando Sol como o novo centro. A esse bloco sonoro sobrepõem-se mais dois blocos: Mib-Sib nas trompas e Ré-Lá nos trombones. Esse procedimento pode ser observado no Exemplo 4.
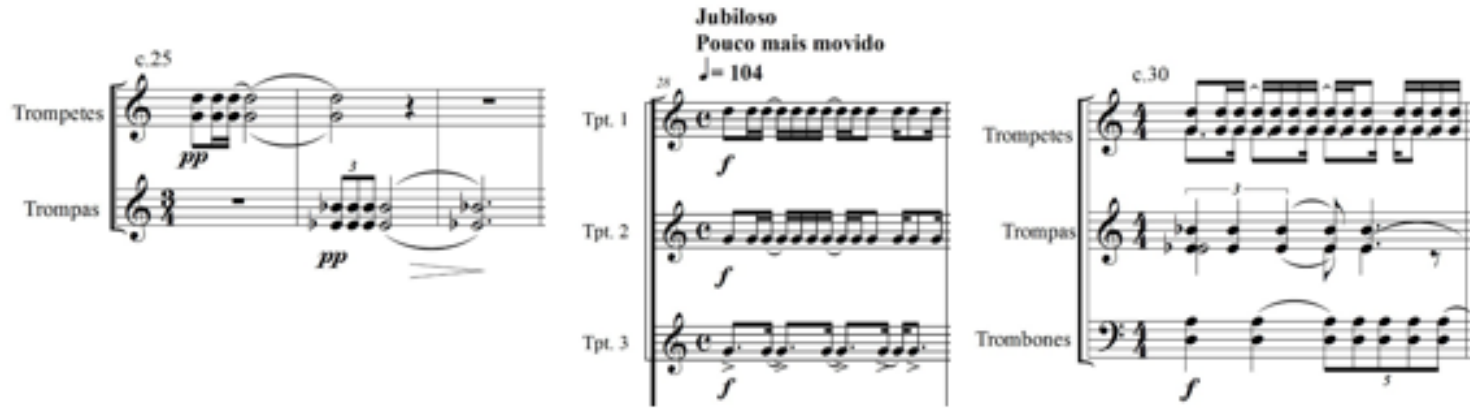

Exemplo 4: Almeida Prado, Metalosfera - Blocos sonoros 1ํㅡㄹ e $2^{\underline{a}}$ seções

\footnotetext{
${ }^{3}$ Considerando-se o fato de que o sistema Transtonal utiliza materiais do tonal e do atonal, julgamos coerente adotar termos da linguagem tonal a fim de tornar mais claro o texto.
} 
Uma nova sequência de quintas inicia-se no compasso 33, tendo as alturas Lá-Mi nos trompetes, às quais se sobrepõem Mib-Sib e Ré-Lá, assinalando o centro Ré. Nesta seção, a cadência ocorre de forma bastante ortodoxa do ponto de vista tonal: Mib e Lá correspondem à Napolitana e Dominante de Ré e, a despeito dos blocos sonoros não apresentarem o intervalo de terça, concluímos que não ocorre uma neocadência, conforme propõe a teoria do compositor.

O intervalo Sib-Fá surge no compasso 39, sobreposto aos blocos Mi-Si e Ré-Lá, abrindo a última seção do primeiro movimento, como no Exemplo 5.
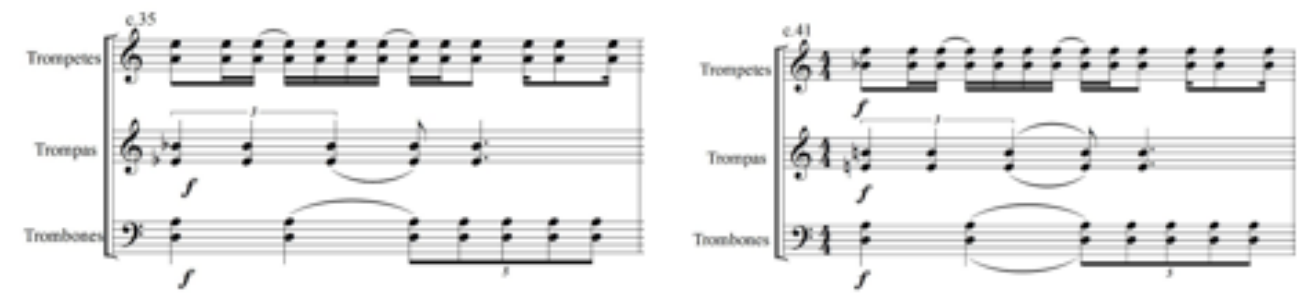

Exemplo 5: Almeida Prado, Metalosfera - blocos sonoros sobrepostos

A neocadência que finaliza a terceira seção indica o centro Lá. O caminho harmônico utilizado pelo compositor é formado por três intervalos de 5J: Sib-Fá, Mi-Si e Ré-Lá. Considerando apenas os dois primeiros intervalos, dentro de um contexto tonal ortodoxo, concluiríamos que o centro seria Lá. Isto porque Sib-Fá e Mi-Lá correspondem, respectivamente, à Napolitana e Dominante de Lá. Almeida Prado contraria essa regra, concluindo no centro Ré. Desta forma, o caráter ambíguo deste trecho consiste na dualidade Lá ou Ré, onde o primeiro é indicado pela formação cadencial e o segundo afirmado pelo compositor. Notase, conforme o Exemplo 6, a intenção do compositor de alterar o campo de ressonância, agregando novos timbres.

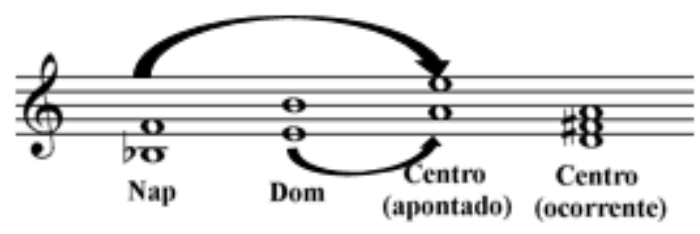

Exemplo 6: Almeida Prado, Metalosfera, neocadência da 3ª seção

O $1^{\circ}$ movimento conclui afirmando o centro Ré, por meio do intervalo RéLá, ratificando o princípio de que a $5 \mathrm{~J}$ é o elemento estrutural sobre o qual todo o primeiro movimento da peça está construído. Conforme se nota no Exemplo 7, há o retorno da $3 \mathrm{M}$ ao bloco de $5 \mathrm{~J}$, caracterizando uma área de ressonância com inflexão tonal. 


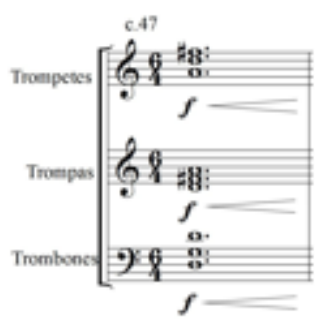

Exemplo 7: Almeida Prado, Metalosfera, afirmação do centro Ré

A organização do material utilizado no $1^{\mathrm{o}}$ movimento é mostrada no Exemplo 8. Os materiais são, na ordem: 5J; inserção da 3M; sobreposição de blocos sonoros com intervalos de $2 \mathrm{~m}, 3 \mathrm{M}, 4 \mathrm{~A}$ e $5 \mathrm{~J}$. Esta é a síntese do material utilizado no $1^{\underline{o}}$ movimento e que será desenvolvido nos II e III movimentos.

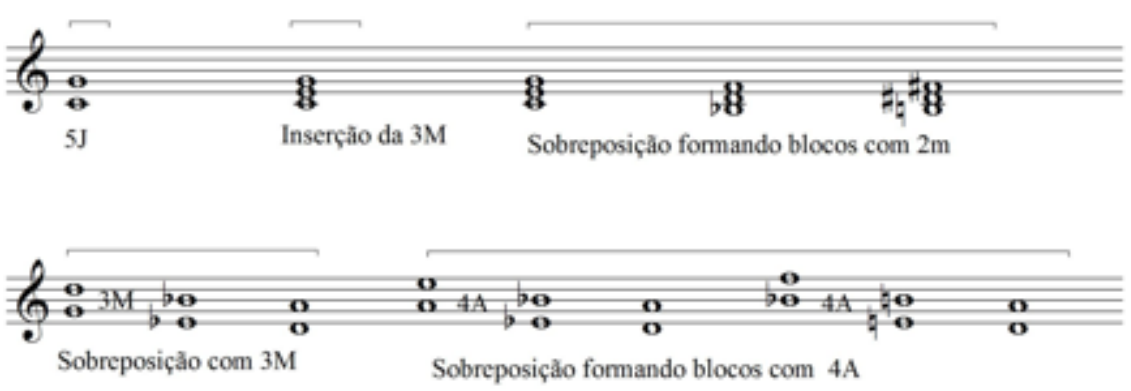

Exemplo 8: Almeida Prado, Metalosfera, resumo da estrutura harmônica do $1^{\circ}$ movimento

O segundo movimento, em forma de tema e variações, inicia-se com os trompetes apresentando uma variação do material exposto no movimento anterior. No primeiro movimento os blocos sonoros (estrutura vertical) compunham-se estritamente de intervalos de 3M e 5J. Eram, portanto, meras tríades o que não justificaria o nome de bloco, não fosse a ocorrência adiante, em procedimentos semelhantes, de outros blocos com outras formações intervalares. No segundo movimento a 3M é substituída pela 4A. Segundo Almeida Prado, este tema está construído sobre uma série de treze sons com uma concentração de intervalos justos de quintas e aumentados de quartas. Temos novamente uma fusão entre a linguagem tonal e a atonal. Nesta sequência de treze sons, as alturas repetidas não ocorrem no mesmo instrumento, podendo ser consideradas diferentes no que se refere ao timbre e aos efeitos de ressonâncias, conforme é mostrado no Exemplo 9. 


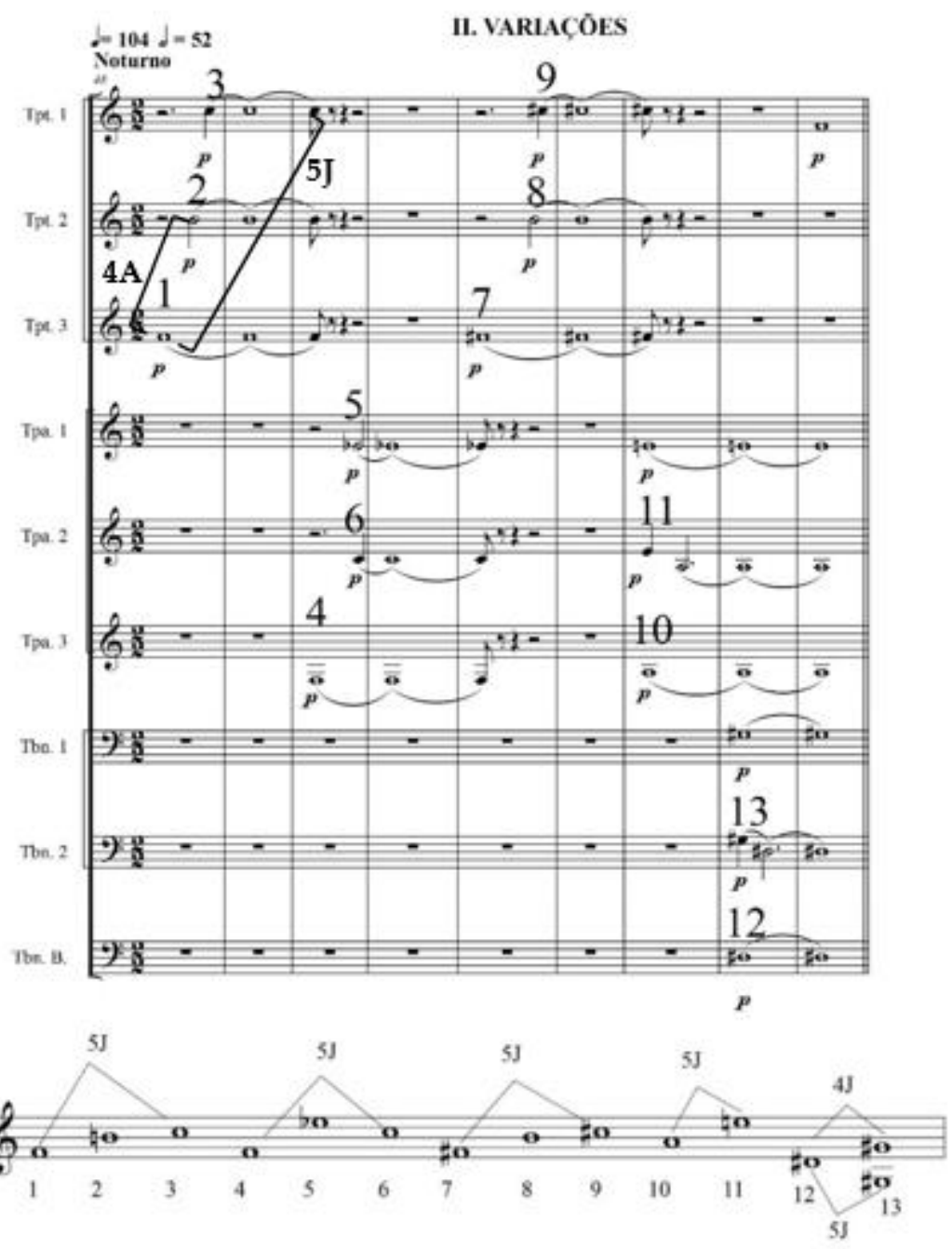

Exemplo 9: Almeida Prado, Metalosfera, 2o movimento intervalo de $4 \mathrm{~A}$ e série de treze sons

A Variação I apresenta, como elemento estrutural, o material gerador ocorrente no Tema, mesclado entre os naipes dos metais.

Na Variação II notamos o intervalo de 5J descendente nos trompetes, enquanto nos trombones, ocorre o material apresentado no tema, ou seja, a 4A seguida da 5J. O material gerador ocorre na Variação III no formato de inversão espelho e com variação.

Uma harmonia quartal compõe a Variação IV, onde prevalece o intervalo de 4J na estruturação harmônica. Nos trombones esse material ocorre em movimentação diatônica ascendente; nos trompetes em cromático ascendente e nas trompas em cromático descendente. Novamente sublinhamos a intenção do compositor em agregar ressonâncias ao material timbrístico.

As Variações V e VI recapitular o material gerador, havendo uma intensificação rítmica e um adensamento da textura. 
Na Variação VII o compositor emprega, em cada um dos instrumentos, a mesma sequência de alturas repetidamente - 4A e 5J - com diminuição rítmica. Os intervalos ocorrentes são os mesmos apresentados no material gerador, com ou sem inversão. Uma síntese do material ocorrente nas sete variações é apresentada na Variação VIII, onde o compositor sugere a ideia de retorno à estrutura do $1^{\mathrm{o}}$ movimento, ou seja, a tríade maior (vide Tabela 1 ).

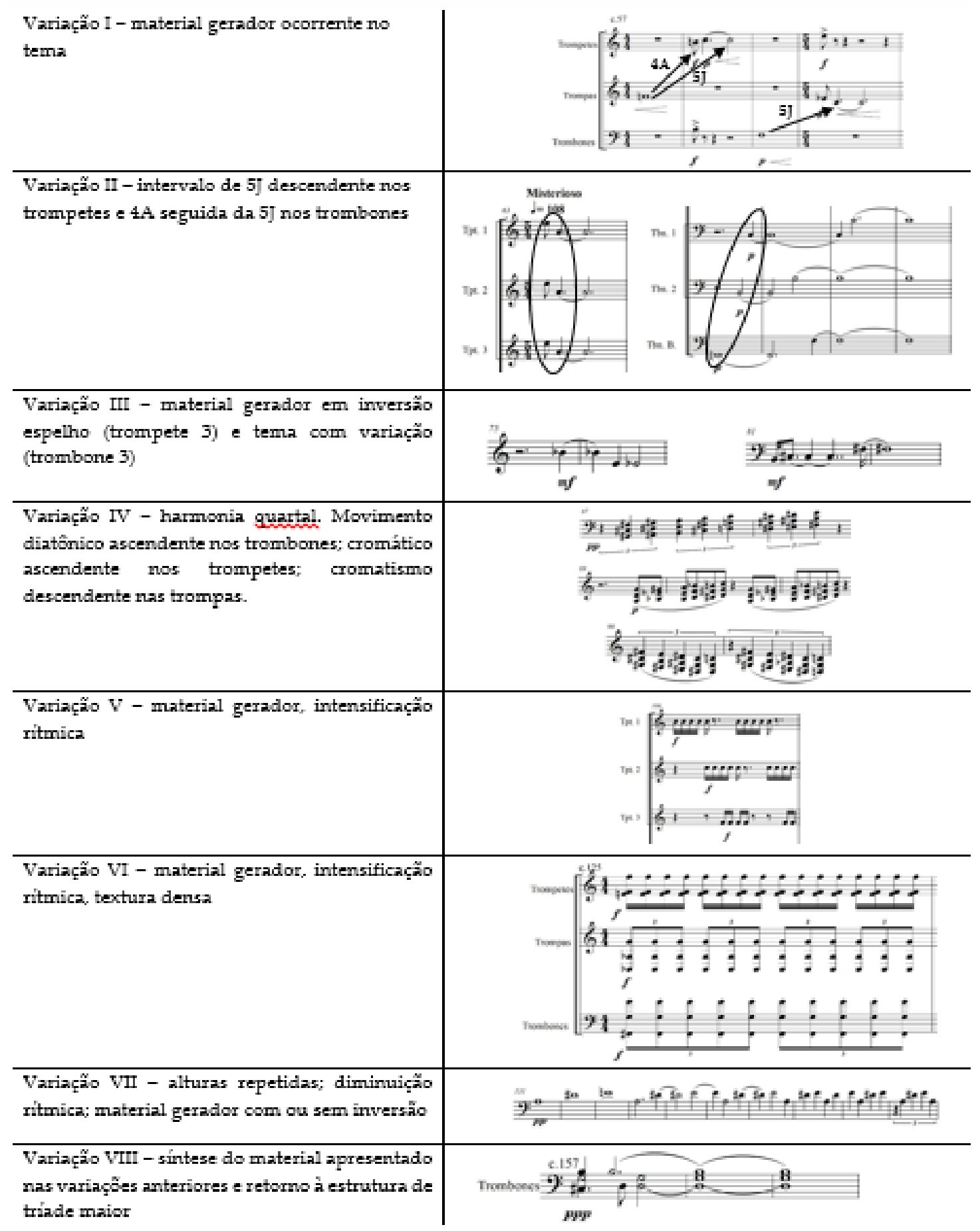

Tabela 1: Almeida Prado, Metalosfera, 2oㅡ movimento - estrutura das variações 
No que se refere ao centro que ocorre no $2^{\underline{0}}$ movimento, consideramos oportuno tecer comentários sobre os centros apontados em cada variação, e, posteriormente, organizar, por meio dessas informações, a estrutura das neocadências deste trecho da peça.

O centro, no $2^{\underline{o}}$ movimento, está organizado no seguinte formato: o tema tem como centro Sol\#, polarizado pela 5J, Ré\#. A Variação I tem centro em Dó\#, que polariza, por meio de um intervalo de 4A, a altura Fá, centro da Variação II. Embora a escrita permita a ambiguidade de outros centros, nota-se que ao final desta variação há uma convergência para a altura Fá.

Na Variação III as alturas formam uma coleção cromática e, portanto, não há um centro definido; um bloco sonoro sobre a altura Lá (Lá-Dó\#-Mi-Sol\#-Sib) é apresentado na Variação IV.

Quanto à Variação V, o centro é a altura Fá, visto que nos trombones estrutura-se um bloco sonoro formado pelas alturas Fá, Lá e Mi, polarizadas, respectivamente, pelas alturas Fá\#, Sol\# e Ré\#, apresentadas nas trompas. Neste caso a polarização se deu pelo intervalo de segunda menor.

O centro Sol é indicado na Variação VI, por meio da ocorrência de suas sensíveis superior (Láb) na trompa 3 e inferior (Fá\#) no trombone 3.

A Variação VII finaliza-se com centro em Ré, pois nos trombones ocorrem as alturas Lá-Dó\#-Mi-Sol, ou seja, o bloco sonoro que polariza essa altura.

Três centros definidos são apontados na Variação VIII: Lá, apresentado pelos trompetes; Sol, apresentado pelos trombones e Láb, apresentado pelas trompas. Os centros Lá e Sol polarizam o centro Ré, ao mesmo tempo em que são as sensíveis superior e inferior do centro Sol\#, que inicia e finaliza as variações.

Em síntese o centro do segundo movimento é Sol\# (ou Láb). Há centros intermediários nas variações que convergem para o centro principal em que estabelecem com este centro relações de $5 \mathrm{~J}, 4 \mathrm{~A}$ e $2 \mathrm{~m}$, ratificando a unidade de material empregado nesta seção, conforme apontamos na Exemplo 10.

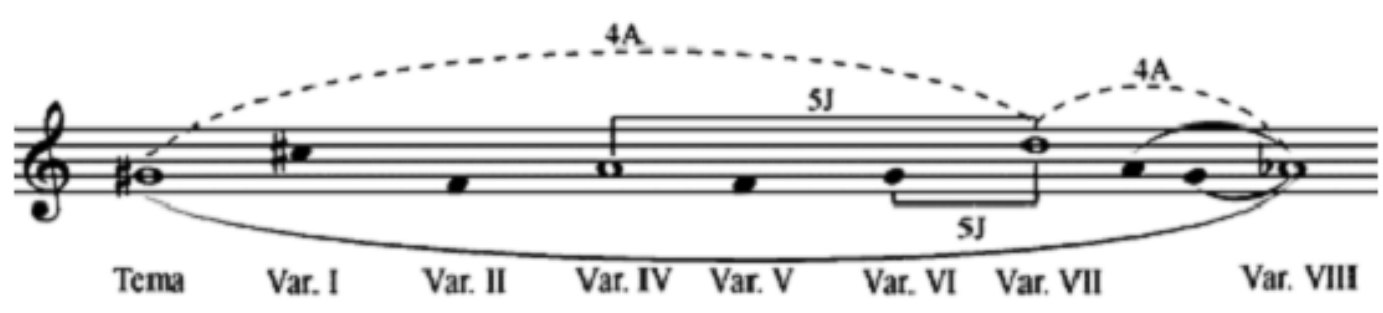

Exemplo 10: Almeida Prado, Metalosfera - centro no $2^{\circ}$ movimento

No $2^{\underline{o}}$ movimento, que se inicia e conclui no centro Sol\#, a neocadência se dá pelo retorno a este centro, enarmonizado. O compositor elabora de forma bem 
evidente uma suposta conclusão no centro Ré, por meio das alturas Sol e Lá, quintas justas, ascendente (dominante) e descendente (subdominante) de Ré.

O final, no entanto, se dá em Láb, de onde se conclui que a polarização é feita por meio das sensíveis superior e inferior desta altura. Mais uma vez, Almeida Prado suscita a ideia de ambiguidade: Ré ou Láb? Aqui se evidencia a intenção de dualismo: a divergência dos intervalos que polarizam os centros - 5J ou $2 \mathrm{~m}$ - e o fato de os dois centros apontados serem antípodas. Ver Exemplo 11.

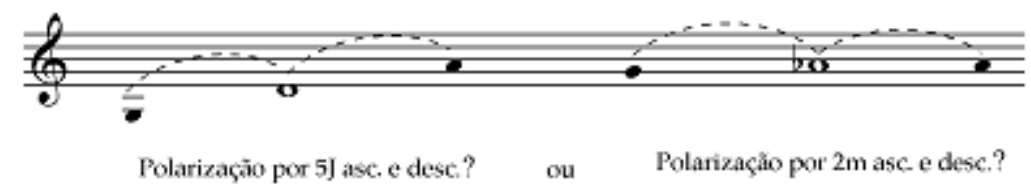

Exemplo 11: Almeida Prado, Metalosfera - neocadência do $2^{\circ}$ movimento

No $3^{\circ}$ movimento (compassos 171-206), o material gerador é apresentado no trompete 1 , na trompa 1 e com variação no trombone 1 .

Assinalamos, a partir do compasso 180, o abandono do intervalo de $4 \mathrm{~A}$ e o retorno a uma estrutura acórdica, pois há um bloco sonoro estruturado em $3 \mathrm{M}$ e 5J. Neste ponto da peça esclarece-se a ruptura com a estrutura atonal e inicia-se o retorno a um modelo tonal, conforme exemplificamos na Exemplo 12.
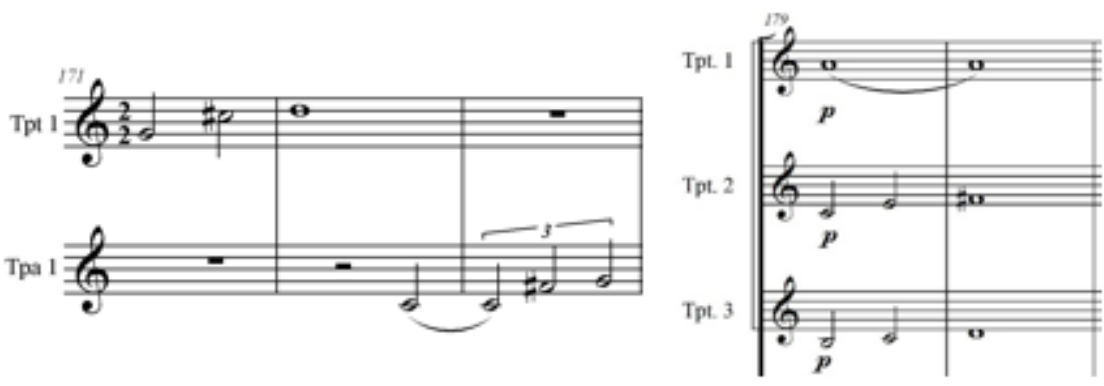

Exemplo 12: Almeida Prado, Metalosfera - retorno ao material triádico, inflexão tonal

Entre os compassos 184-197 há uma transição onde o compositor emprega movimentações diatônicas ascendentes e descendentes, dando início, no compasso 198, a uma movimentação ascendente em terças, preparando a chegada a um bloco sonoro alicerçado em Dó\#, que resolve no centro Sol\# por meio de uma movimentação em 5J ascendente, concluindo a peça, conforme é mostrado no Exemplo 13. 


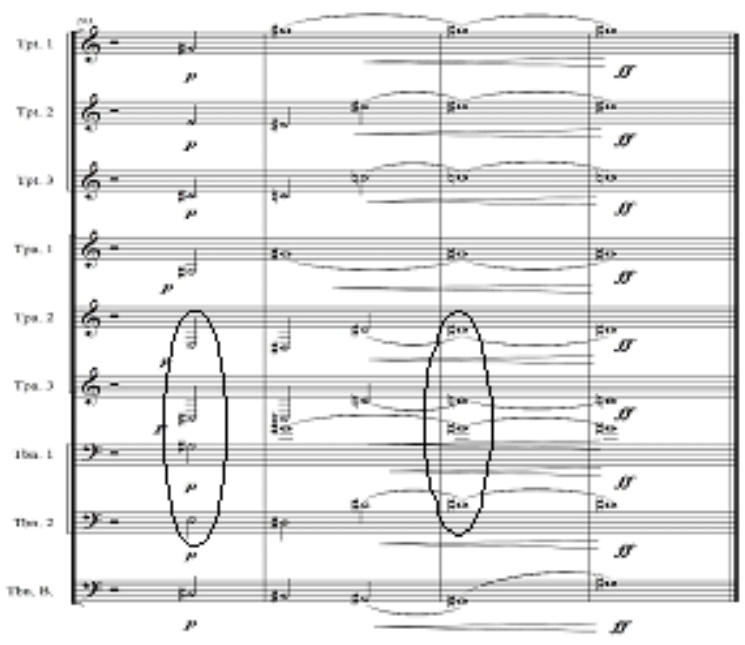

Exemplo 13: Almeida Prado, Metalosfera - conclusão do $3^{\circ}$ movimento

No que se refere ao centro, o compositor adota dois caminhos: na primeira parte deste movimento chega ao centro Láb por meio de sua antípoda, Ré, portanto em uma estrutura atonal. Já na finalização da peça, o centro Sol\# é alcançado por meio do intervalo de 5J - altura Dó\# - logo um modelo tonal. Acrescentamos aqui outro fator ambíguo: Almeida Prado utiliza ora Láb, ora Sol\#, sugerindo dubiedade.

A neocadência se dá pelo caminho da estrutura harmônica que segue para Dó\#, e em um contexto tonal finaliza a peça no centro Sol\#, antípoda de Ré, como ilustramos no Exemplo 14.

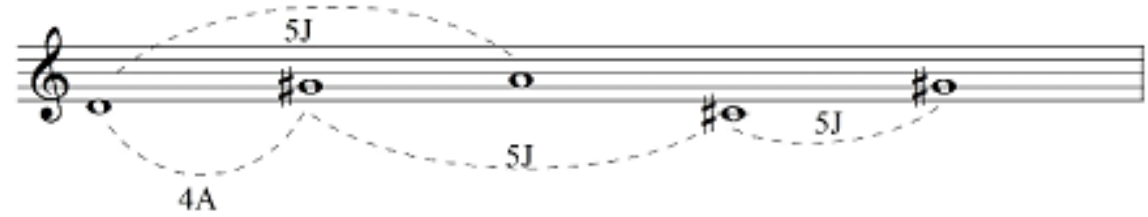

Exemplo 14: Almeida Prado, Metalosfera - Neocadência e conclusão da peça em Sol\#

Quanto à relação entre os centros ocorrentes na peça toda, chegamos à conclusão de que prevalece Sol\#, polarizado pela sua antípoda, Ré. Apontamos a intenção do compositor de empregar um modelo embasado no ciclo de quintas, onde os centros correspondem às duas alturas opostas desta coleção. Novamente há sugestão de ambiguidade. Observe-se o Exemplo 15. 

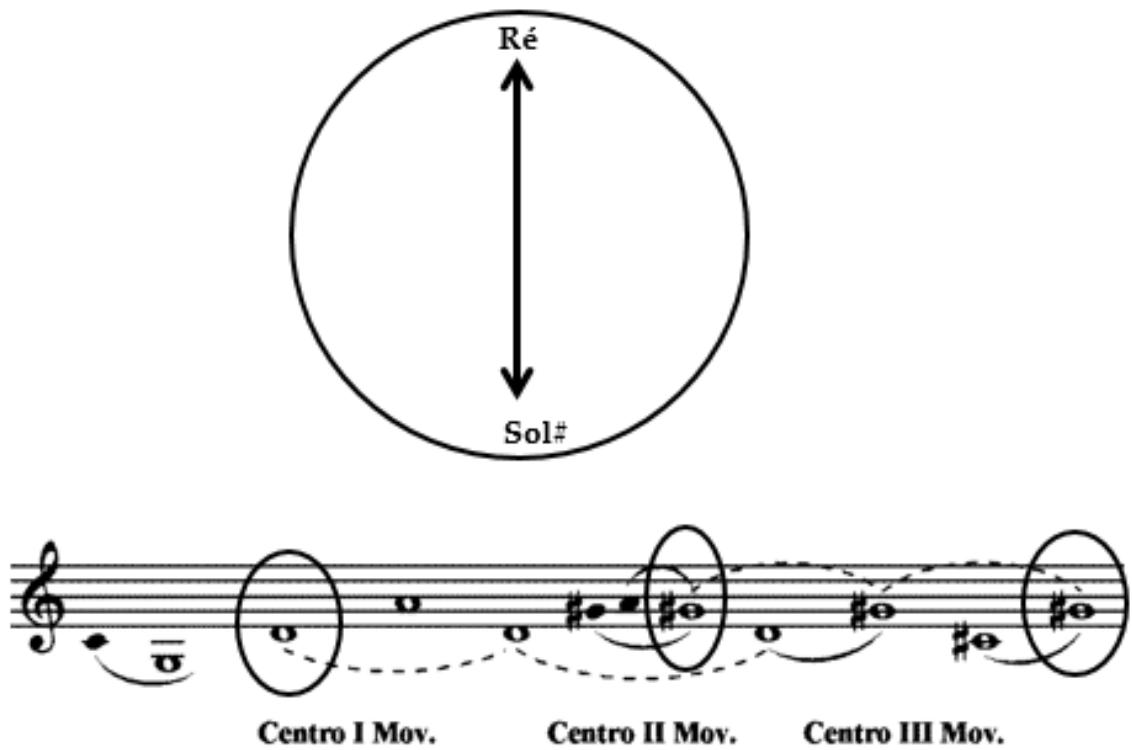

Exemplo 15: Almeida Prado, Metalosfera - centro da peça

Um fator de unidade e coerência é conferido à peça por meio dos centros apontados, pois as alturas correspondentes aos centros de cada movimento resumem o material gerador de Metalosfera.

Verificamos que, combinando as alturas Sol-Do\#-Ré ${ }^{4}$ temos o material gerador apresentado no início do $2^{\circ}$ movimento. Ré-Sol\#-Lá equivalem a esse material transposto. O eixo entre ambos consiste exatamente na altura Ré, o centro que inicia, mas não conclui a peça.

Há novamente uma sugestão de ambiguidade: Ré é o eixo de ligação entre os principais centros ocorrentes na peça, mas não é o centro que a conclui. Mostra-se isso no Exemplo 16.

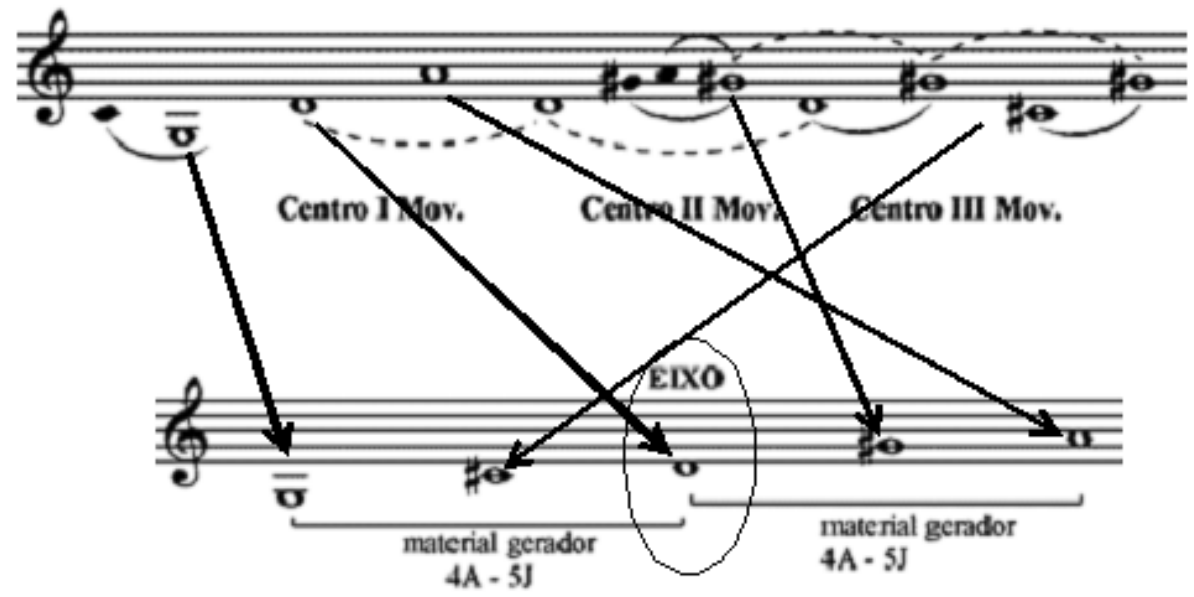

Exemplo 16: Almeida Prado, Metalosfera - Ré como eixo da obra

\footnotetext{
${ }^{4}$ Essas alturas ocorrem no tema, porém transpostas para trompeteem Sib.
} 


\section{Conclusão}

O Sistema Transtonal, proposto pelo compositor Almeida Prado e empregado na peça Metalosfera, é detalhadamente elucidado na análise apresentada neste artigo, principalmente no que tange a três aspectos: ressonância de blocos sonoros; neocadências - caminhos harmônicos diferenciados para indicação de um centro -; e sugestão de ambiguidade.

Metalosfera é integralmente estruturada com blocos sonoros sobrepostos, com maior ou menor duração, de onde derivam múltiplas ressonâncias, conferindo diversidade timbrística à peça, especialmente se considerarmos que a escrita é específica para metais, instrumentos com grande potencial de reverberação de harmônicos. O recurso da repetição é utilizado em toda a obra, visto que os blocos ou materiais são recorrentes.

Com relação ao emprego de neocadências, o compositor se utiliza de caminhos harmônicos idiomáticos ao seu sistema para apontar um centro, ora dentro de uma organização supostamente tonal que conclui em um resultado fortuito, ora apresentando procedimentos originais direcionados à finalização em uma cadência de inflexão tonal.

Concluímos que as neocadências organizadas na peça sempre levam a um termo ambíguo no que se refere à definição de um centro. Esse fator pode ser considerado um entre tantos que a peça apresenta no que se refere à duplicida de de respostas.

A questão da ambiguidade está, portanto, presente em toda a peça. $\mathrm{O}$ próprio Sistema Transtonal traz em si o embate Tonal/Atonal, dois formatos de composição opostos, onde os princípios do primeiro negam os do segundo.

Quanto ao material empregado na peça, temos a ocorrência de um intervalo unificador, a 5J, presente nos três movimentos. Esse intervalo, no entanto, vem acrescido de dois intervalos com caracteres distintos: a 3M, que alude ao sistema tonal e à tríade perfeita maior; e a $4 \mathrm{~A}$, que impossibilita a sobreposição de terças e de organização tonal.

No que concerne aos centros na peça, temos a altura Ré e sua antípoda, Láb. Até mesmo essa antípoda se apresenta de forma dúbia: Sol\# ou Láb. Apesar do centro Ré ser fortemente afirmado no primeiro movimento, essa certeza se esvai nos dois movimentos que se seguem, onde a conclusão se dá em Láb. No entanto, todo o material empregado na peça apresenta, de forma clara, um eixo de intersecção: Ré.

Com essa informação apontamos um último sinal de percepção dupla na peça: há uma unidade extremamente clara na mesma, afirmada pelo fato de todo o material ser resumido em intervalos conectados pela nota Ré. No entanto, essa unidade é declarada por meio da dubiedade "eixo Ré versus centro Láb", duas notas antípodas. 


\section{Referências}

Mariz, Vasco. 2000. História da Música no Brasil. 5a Ed. Rio de Janeiro: Nova Fronteira.

Prado, Almeida. 1985a. Cartas Celestes: Uma Uranografia Sonora Geradora de Novos Processos Composicionais. Tese de doutorado. Universidade de Campinas.

Prado, Almeida. 1985b. Metalosfera. (Partitura). Darmstadt: Tonos. 